\title{
Bortezomib and melphalan as a conditioning regimen for autologous stem cell transplantation in multiple myeloma
}

\author{
Se Ryeon Lee ${ }^{1}$, Seok Jin Kim², Yong Park ${ }^{1}$, Hwa Jung Sung ${ }^{1}$, Chul Won Choi ${ }^{1}$, Byung Soo Kim ${ }^{1}$ \\ ${ }^{1}$ Department of Internal Medicine, Korea University Medical Center, ${ }^{2}$ Department of Medicine, Samsung Medical Center, \\ Sungkyunkwan University School of Medicine, Seoul, Korea
}

p-ISSN 1738-7949 / e-ISSN 2092-9129

DOI: $10.5045 / \mathrm{kjh} .2010 .45 .3 .183$

Korean J Hematol 2010;45:183-7.

Received on April 30, 2010

Revised on July 23, 2010

Accepted on September 2, 2010

\section{Background}

High-dose melphalan $\left(200 \mathrm{mg} / \mathrm{m}^{2}\right)$ with autologous stem cell transplantation (ASCT) is the standard treatment for young patients with multiple myeloma (MM). However, the response rates after ASCT are often unsatisfactory. We performed a pilot study by using bortezomib-melphalan as conditioning regimen for ASCT in Korean patients with MM.

\section{Methods}

The conditioning regimen consisted of administration of intravenous infusion of bortezo$\mathrm{mib} 1.0 \mathrm{mg} / \mathrm{m}^{2}$ on days -4 and -1 and melphalan $50 \mathrm{mg} / \mathrm{m}^{2}$ (day -4 ) and $150 \mathrm{mg} / \mathrm{m}^{2}$ (day -1). In this study, we enrolled 6 newly diagnosed patients and 2 patients with relapse.

Results

The disease status of the 6 newly diagnosed patients at ASCT was as follows: 1 complete remission (CR), 1 very good partial remission (VGPR), and 4 partial remissions (PRs). The disease status of the 2 relapsed patients at ASCT was PR. All patients except 1 showed adequate hematologic recovery after ASCT. The median time for the absolute neutrophil counts to increase over 500/ $\mathrm{mm}^{3}$ was 13 days (range, 10-19 days). Six patients with VGPR or PR at the time of transplantation showed an improvement in response to CR after ASCT. The patients were followed up without any maintenance treatment after ASCT except 1 patient who died during ASCT. During the follow-up period, CR was maintained in 3 newly diagnosed patients, but the other 4 patients, including 2 newly diagnosed patients, relapsed.

\section{Conclusion}

Conditioning regimen consisting of bortezomib and melphalan may be effective for ASCT in MM; however, the feasibility of this regimen should be further evaluated in large study populations.

Key Words Multiple myeloma, Bortezomib, Melphalan

\section{INTRODUCTION}

Intravenous administration of high-dose of melphalan followed by autologous stem cell transplantation (ASCT) induces higher response rates and improved treatment outcomes compared to that with standard dose melphalan, as reported in previous randomized trials $[1,2]$. High-dose melphalan $\left(200 \mathrm{mg} / \mathrm{m}^{2}\right)$ has been widely used in patients with multiple myeloma (MM) and is known as the most effective available conditioning regimen for MM [3]. However, relapse is still common, and the response rates after ASCT are often unsatisfactory. A high-dose conditioning regimen mainly contributes to the efficacy of ASCT by the cytoreduction effect, and thus, development of a more effective conditioning regimen may help in improving the outcome of ASCT. However, convincing evidence indicating that any conditioning regimen is superior to high-dose melphalan (200 $\mathrm{mg} / \mathrm{m}^{2}$ ) without additional toxicities is not available [3-6].

Bortezomib (VELCADE; Millennium Pharmaceuticals, Inc., Cambridge, MA, USA and Johnson \& Johnson LLC, Raritan, NJ, USA) is the first proteasome inhibitor approved for MM therapy. The efficacy of bortezomib has been shown in previous clinical trials with a large study population [7-9]. In addition, bortezomib has shown synergistic effects with chemotherapeutic agents in a preclinical model $[7,8,10]$. 
The efficacy of administration of bortezomib and melphalan has suggested synergistic effects between these 2 drugs [11, 12]. Thus, the combination of bortezomib with high-dose melphalan as conditioning regimen may present a promising approach to improve response rates in MM patients after ASCT. A group from the University of Arkansas suggested the possibility of a bortezomib-melphalan conditioning regimen in an abstract presented in the annual meeting of American Society of Hematology 2004 (Hollmig K, et al. Blood 2004; Abstract \#929). Therefore, we performed a pilot study in which we combined bortezomib and high-dose melphalan as a conditioning regimen for ASCT in Korean patients with MM.

\section{MATERIALS AND METHODS}

Patients under 65 years of age with symptomatic MM were included in this study provided that they were eligible for high-dose therapy (HDT) and had a non-progressive disease at the time of ASCT. The exclusion criteria were: a serum creatinine level of $\geq 2.5 \mathrm{mg} / \mathrm{dL}$ at the time of HDT; liver insufficiency, e.g., a total serum bilirubin level of 2.0 $\mathrm{mg} / \mathrm{dL}$, serum aspartate/alanine aminotransferase levels or alkaline phosphatases level more than 3.0×the upper limit of normal; a left ventricular ejection fraction of $\leq 50 \%$, and a pulmonary diffusion capacity of $\leq 50 \%$ of predicted; a grade 3 or worse peripheral neuropathy, significant comorbid disease that would preclude ASCT; and a history of any other malignant disease within the past 5 years, except curatively treated non-melanoma skin cancer or in situ carcinoma of cervix uteri.

The conditioning regimen was designed according to the previous report (Hollmig K, et al. Blood 2004; Abstract \#929), and it was as follows. On day -4 , bortezomib $\left(1.0 \mathrm{mg} / \mathrm{m}^{2}\right)$ and melphalan $\left(50 \mathrm{mg} / \mathrm{m}^{2}\right)$ were infused intravenously (IV). Bortezomib $\left(1.0 \mathrm{mg} / \mathrm{m}^{2}\right)$ and melphalan $\left(150 \mathrm{mg} / \mathrm{m}^{2}\right)$ were infused IV on day-1, followed by stem cell support on day 0 (Fig. 1). All patients received standard supportive care measures, including growth factor support, blood transfusions, and prophylactic or therapeutic antibiotics. Prophylactic antibiotics, including acyclovir (400 mg q $12 \mathrm{~h}$ ) were used from day -5 . We evaluated the response status at 6

$\left.\right|_{\text {Day-4 }} ^{\text {M50 }}$

Fig. 1. Schematic diagram of the bortezomib and melphalan conditioning regimen. $\mathrm{B}$, bortezomib $1 \mathrm{mg} / \mathrm{m}^{2} ; \mathrm{M} 50$, melphalan $50 \mathrm{mg} / \mathrm{m}^{2}$; M150, melphalan $150 \mathrm{mg} / \mathrm{m}^{2}$; PBSC, peripheral blood stem cell. weeks after ASCT according to the International Myeloma Working Group Criteria. Because serum free light chain assay was not available in our institute during this study, stringent complete remission (sCR) could not be evaluated. Toxicities were graded according to the National Cancer Institute Common Toxicity Criteria of Adverse Events, version 3.0. Overall survival (OS) was measured from the date of ASCT to the date of death or last follow-up visit. Progression-free survival (PFS) was defined as the time from ASCT to disease progression or death. Patients were followed up to December 2009. The institutional review board of Korea University Medical Center approved this study.

\section{RESULTS}

Between April 2005 and January 2008, 8 patients received bortezomib and high-dose melphalan conditioning prior to ASCT. Six newly diagnosed patients (No. 1-6) received 4-6 cycles of vincristine, adriamycin, and dexamethasone (VAD) combination chemotherapy as induction treatment. The disease statuses of these 6 patients at the time of ASCT were 1 complete remission (CR), 1 very good partial remission (VGPR), and 4 partial remissions (PR). Two relapsed patients received 2 kinds of treatment (VAD and thalidomide/dexamethasone) before ASCT, and their disease status was PR (Table 1). Peripheral blood stem cells were mobilized using granulocyte colony-stimulatory factor (G-CSF) infusion (filgrastim, $10 \mu \mathrm{g} / \mathrm{kg}$ IV for 3 days) in 4 patients, cyclophosphamide mobilization chemotherapy plus G-CSF infusion was performed in the remaining 4 patients. The median number of collected CD34+ cells was $4.5 \times 10^{6} / \mathrm{kg}$ (range, $3.5-9.0 \times 10^{6} / \mathrm{kg}$ ). The median time of the absolute neutrophil count to rise over $500 / \mathrm{mm}^{3}$ was 13 days (range, 10-19 days), and the median time of the platelet count to rise over $20,000 / \mathrm{mm}^{3}$ was 17 days (range, 14-20 days). Seven patients experienced an episode of febrile neutropenia. Although all of these patients recovered after empirical antibiotics therapy, 1 patient (No. 6) developed respiratory distress at around day +7 . This patient died due to right upper lobar pneumonia on day +11 . The most frequently reported non-hematologic toxicities, except fever, were mucosites, and these toxicities were manageable (Table 2). It should be noted that peripheral neuropathy was present at the time of ASCT in 2 patients and did not worsen after conditioning. Non-hematologic toxicities, including peripheral neuropathy, were unremarkable. Six patients with VGPR or PR at the time of transplantation showed an improvement in response to CR after ASCT (Table 1). The patients were followed up after ASCT without any maintenance treatment. The median follow-up duration was 27.3 months (range, 4.0-51.7 months) and CR was maintained in 3 newly diagnosed patients, but the other 4 patients, including 2 newly diagnosed patients, relapsed (Table 1). 
Table 1. Summary of patients.

\begin{tabular}{|c|c|c|c|c|c|c|c|c|}
\hline & No. 1 & No. 2 & No. 3 & No. 4 & No. 5 & No. 6 & No. 7 & No. 8 \\
\hline Gender & Male & Male & Female & Female & Female & Male & Male & Male \\
\hline $\operatorname{Age}^{\text {a) }}$ & 65 & 52 & 35 & 39 & 37 & 58 & 41 & 38 \\
\hline ECOG performance status ${ }^{\mathrm{a})}$ & 2 & 2 & 2 & 3 & 0 & 3 & 3 & 2 \\
\hline DS stage & II A & II A & II A & III A & IIA & IIIA & IIIB & IIIA \\
\hline ISS stage ${ }^{c)}$ & III & ॥ & 1 & II & II & ॥ & III & II \\
\hline Extramedullary involvement & $\begin{array}{l}\text { Lumbosacral } \\
\text { spines }\end{array}$ & $\begin{array}{l}\text { Thoracic } \\
\text { spines }\end{array}$ & $\begin{array}{l}\text { Lumbar } \\
\text { spines and } \\
\text { spleen }\end{array}$ & $\begin{array}{l}\text { Thoracic } \\
\text { spines and } \\
\text { both ribs }\end{array}$ & $\begin{array}{l}\text { Thoracic } \\
\text { spines }\end{array}$ & $\begin{array}{l}\text { Whole } \\
\text { spines }\end{array}$ & $\begin{array}{c}\text { Kidney and } \\
\text { lumbar } \\
\text { spines }\end{array}$ & $\begin{array}{l}\text { Lumbosacral } \\
\text { spines }\end{array}$ \\
\hline Serum beta-2 microglobulin (mg/L) & 8.68 & 3.8 & 2.09 & 3.64 & 2.46 & 5.47 & 17.08 & 3.53 \\
\hline Serum albumin (g/dL) & 4.3 & 5.5 & 4.5 & 4.2 & 3.3 & 2.4 & 4.6 & 3.5 \\
\hline Serum creatinine $(\mathrm{mg} / \mathrm{dL})$ & 1.1 & 1.2 & 0.7 & 0.8 & 0.9 & 0.9 & 6.4 & 0.9 \\
\hline Type & $\begin{array}{l}\text { Lamda } \\
\text { light chain }\end{array}$ & $\begin{array}{c}\text { Non-secretory } \\
\text { type }\end{array}$ & IgG, kappa & IgD, lamda & IgG lambda & IgG, kappa & IgG, kappa & $\begin{array}{l}\text { Lamda light } \\
\text { chain }\end{array}$ \\
\hline M-protein & $\begin{array}{l}5.1 \mathrm{~g} / 24 \mathrm{~h} \\
\text { urine }\end{array}$ & $\begin{array}{c}\text { Not } \\
\text { detectable }\end{array}$ & $1.36 \mathrm{~g} / \mathrm{dL}$ & $1.30 \mathrm{~g} / \mathrm{dL}$ & $5.21 \mathrm{~g} / \mathrm{dL}$ & $5.56 \mathrm{~g} / \mathrm{dL}$ & $7.8 \mathrm{~g} / \mathrm{dL}$ & $\begin{array}{l}7.8 \mathrm{~g} / 24 \mathrm{hr} \\
\text { urine }\end{array}$ \\
\hline Bone marrow plasma cell (\%) & $40.2 \%$ & $55.3 \%$ & $15.0 \%$ & $30.5 \%$ & $18.0 \%$ & $66.2 \%$ & $70.3 \%$ & $21.0 \%$ \\
\hline Chromosome & Normal & Normal & Normal & Normal & Normal & Normal & Normal & del $13 q$ \\
\hline Disease status at ASCT & $\mathrm{CR}$ & VGPR & $\mathrm{PR}$ & PR & $\mathrm{PR}$ & $\mathrm{PR}$ & PR & $\mathrm{PR}$ \\
\hline Disease status after ASCT & CR & $\mathrm{CR}$ & $\mathrm{CR}$ & $\mathrm{CR}$ & $\mathrm{CR}$ & NA & $\mathrm{CR}$ & CR \\
\hline Infused CD34+cells $/ \mathrm{kg}$ of recipient & $4.5 \times 10^{6}$ & $6.0 \times 10^{6}$ & $9.0 \times 10^{6}$ & $3.5 \times 10^{6}$ & $4.7 \times 10^{6}$ & $3.8 \times 10^{6}$ & $7.8 \times 10^{6}$ & $4.8 \times 10^{6}$ \\
\hline ANC $>500 / \mu \mathrm{L}$ from ASCT & $+\mathrm{D} 13$ & $+\mathrm{D} 18$ & $+\mathrm{D} 10$ & $+\mathrm{D} 11$ & $+\mathrm{D} 14$ & NA & +D13 & +D19 \\
\hline Platelet $>20,000 / \mu \mathrm{L}$ from ASCT & $+\mathrm{D} 14$ & $+\mathrm{D} 20$ & $+\mathrm{D} 10$ & $+\mathrm{D} 11$ & $+\mathrm{D} 17$ & NA & $+\mathrm{D} 17$ & $+\mathrm{D} 20$ \\
\hline Relapse after ASCT & Yes & Yes & No & No & No & NA & Yes & Yes \\
\hline Current status & Alive & Alive & Alive & Alive & Alive & Death & Death & Death \\
\hline Progression-free survival (months) & 40.2 & 8.1 & 22.5 & 22.1 & 15.5 & NA & 7.4 & 2.6 \\
\hline Overall survival (months) & 59.5 & 52.8 & 36.3 & 26.2 & 23.1 & 4.1 & 30.3 & 7.1 \\
\hline
\end{tabular}

${ }^{\text {a) }}$ Age and performance status at diagnosis, ${ }^{\text {b) }}$ Durie-salmon stage, ${ }^{\mathrm{c})}$ International staging system stage.

Abbreviations: No, number; ECOG, eastern cooperative oncology group; DS stage, Durie-salmon stage; ISS stage, International staging system stage; ANC, absolute neutrophil count; ASCT, autologous stem cell transplantation; NA, not applicable; CR, complete remission; VGPR, very good partial remission; PR, partial remission.

Table 2. Non-hematologic toxicities.

\begin{tabular}{ll}
\multicolumn{1}{c}{ Non-hematologic toxicities } & $\mathrm{N}(\%)$ \\
\hline Fever & $8(100)$ \\
Documented pneumonia & $1(12.5)$ \\
Documented Gram (+) bacteremia & $1(12.5)$ \\
Mucositis & \\
All grades & $4(50.0)$ \\
Grade 3 or 4 & $1(25.0)$ \\
Diarrhea & \\
All grades & $1(12.5)$ \\
Grade 3 or 4 & $0(0.0)$ \\
Peripheral neuropathy & \\
De novo & $0(0.0)$ \\
Pre-existing & $2(25.0)$ \\
Dermographic/allergic reaction & $1(12.5)$ \\
\hline
\end{tabular}

\section{DISCUSSION}

Since the introduction of bortezomib for the treatment of MM, few reports have addressed the feasibility of using a combination of bortezomib plus melphalan as a conditioning regimen [13, 14]. A group from the University of Arkansas reported an overall response rate of $73 \%$ with adequate bone marrow recovery: the median time to recovery of the absolute neutrophil count $\left(>1,000 / \mathrm{mm}^{3}\right)$ and platelet count $(>$ $50,000 / \mathrm{mm}^{3}$ ) was 13 and 17 days, respectively (Hollmig $\mathrm{K}$, et al. Blood 2004; Abstract \#929). A randomized phase I trial of melphalan plus bortezomib as conditioning regimen for ASCT also showed a safe profile with engraftment kinetics (Lonial S, et al. Blood 2007;110:288a; Abstract \#949). Recently, the Intergroupe Francophone du Myelome (IFM) phase II trial reported that conditioning using bortezomib/melphalan produced almost $70 \%$ of CR and VGPR with no toxic death [14].

Although the conditioning regimen, including bortezomib was variable in previous studies, our conditioning regimen was designed according to the first report using the combination of bortezomib and melphalan (Hollmig K, et al. Blood 2004; Abstract \#929). Because bortezomib should be administered with an interval of 72 hours, bortezomib was infused on day- 4 and -1 . To achieve a synergistic effect of the 2 drugs, bortezomib was administered on the same day as melphalan, similar to the other regimen consisting of bortezomib $\left(1.3 \mathrm{mg} / \mathrm{m}^{2}\right)$ and melphalan $\left(50 \mathrm{mg} / \mathrm{m}^{2}\right)$ given on day -6 and -3 [13]. Thus, we divided the dose of melphalan $\left(200 \mathrm{mg} / \mathrm{m}^{2}\right.$ into $50 \mathrm{mg} / \mathrm{m}^{2}$ and $\left.150 \mathrm{mg} / \mathrm{m}^{2}\right)$ to achieve a 
synergism, while maintaining the intensity of high-dose melphalan $\left(200 \mathrm{mg} / \mathrm{m}^{2}\right)$.

Our results indicated that the addition of bortezomib in the conditioning regimen dramatically improved CR from $11 \%$ to $35 \%$. Furthermore, the response rate after ASCT was not different between the VAD induction group and the bortezomib/dexamethasone group. Therefore, it is possible that a bortezomib-containing conditioning regimen could improve the quality of response induced by VAD. Our results also showed a high response rate with adequate bone marrow recovery and unremarkable non-hematologic toxicities. This improvement in the response after ASCT might be related to the synergy between bortezomib and melphalan that was shown in the previous studies [11, 12].

The median duration of PFS of all patients was 15.3 months and the median PFS of the 6 newly diagnosed patients was 21.1 months. Although this result might be comparable with previous single ASCT studies in newly developed MM patients $[15,16]$, the improvement in the degree of response following bortezomib plus high-dose melphalan conditioning did not translate into an improvement in PFS in this study. However, caution should be exercised when interpreting the results of a pilot study that has a small study population.

Although the mechanism of the synergistic effect remains to be clarified, several different potential mechanisms of bortezomib may be involved, including induction of apoptosis, blockade of nuclear factor kappa B (NF- $\mathrm{B})$, and inhibition of cell-cycle progression [17, 18]. Recently, it has been reported that the sequence of administration of bortezomib and melphalan could be important when they were used as a conditioning regimen (Lonial S, et al. Blood 2007;110:288a; Abstract \#949). Thus, melphalan followed by bortezomib may be superior to bortezomib followed by melphalan because bortezomib may upregulate the anti-apoptotic protein myeloid cell leukemia 1 (MCL-1) [19]. In this study, melphalan was administered before bortezomib, but its efficacy should be confirmed by further studies with larger study populations.

Although 1 treatment-related death occurred, the addition of bortezomib may not have amplified the toxicity of melphalan in the light of adequate overall bone marrow recovery. Our case of toxic death might not be associated with bortezomib, because the radiologic findings of our patient were different from those of bortezomib-induced lung disease and showed typical upper lobar pneumonia [20, 21]. While peripheral neuropathy may be the main adverse effect of bortezomib, there was no de novo case of peripheral neuropathy in this study. It should be noted that peripheral neuropathy was present at the time of ASCT in 2 patients and did not worsen after conditioning. Other non-hematologic toxicities associated with the bortezomib-melphalan conditioning regimen were relatively mild and manageable. Only 1 patient experienced grade 3 mucositis. Because responders showed long-term sustained response after ASCT, this effect could be prolonged if an appropriate maintenance therapy could be used after bortezomib-melphalan conditioning following
ASCT.

In conclusion, this is the first report on the efficacy of bortezomib plus high-dose melphalan therapy in Asian patients with MM. We believe that this conditioning regimen may be more effective for ASCT than melphalan alone. However, the feasibility of this conditioning regimen should be further evaluated in a larger study population.

\section{REFERENCES}

1. Child JA, Morgan GJ, Davies FE, et al. High-dose chemotherapy with hematopoietic stem-cell rescue for multiple myeloma. $\mathrm{N}$ Engl J Med 2003;348:1875-83.

2. Palumbo A, Triolo S, Argentino C, et al. Dose-intensive melphalan with stem cell support (MEL100) is superior to standard treatment in elderly myeloma patients. Blood 1999;94:1248-53.

3. Moreau P, Facon T, Attal M, et al. Comparison of $200 \mathrm{mg} / \mathrm{m}(2)$ melphalan and 8 Gy total body irradiation plus $140 \mathrm{mg} / \mathrm{m}(2)$ melphalan as conditioning regimens for peripheral blood stem cell transplantation in patients with newly diagnosed multiple myeloma: final analysis of the Intergroupe Francophone du Myélome 9502 randomized trial. Blood 2002;99:731-5.

4. Desikan KR, Tricot G, Dhodapkar M, et al. Melphalan plus total body irradiation (MEL-TBI) or cyclophosphamide (MEL-CY) as a conditioning regimen with second autotransplant in responding patients with myeloma is inferior compared to historical controls receiving tandem transplants with melphalan alone. Bone Marrow Transplant 2000;25:483-7.

5. Einsele H, Bamberg M, Budach W, et al. A new conditioning regimen involving total marrow irradiation, busulfan and cyclophosphamide followed by autologous PBSCT in patients with advanced multiple myeloma. Bone Marrow Transplant 2003;32: 593-9.

6. Anagnostopoulos A, Aleman A, Ayers G, et al. Comparison of high-dose melphalan with a more intensive regimen of thiotepa, busulfan, and cyclophosphamide for patients with multiple myeloma. Cancer 2004;100:2607-12.

7. Richardson PG, Barlogie B, Berenson J, et al. A phase 2 study of bortezomib in relapsed, refractory myeloma. $\mathrm{N}$ Engl J Med 2003;348:2609-17.

8. Jagannath S, Barlogie B, Berenson J, et al. A phase 2 study of two doses of bortezomib in relapsed or refractory myeloma. $\mathrm{Br} \mathrm{J}$ Haematol 2004;127:165-72.

9. Richardson PG, Sonneveld P, Schuster MW, et al. Bortezomib or high-dose dexamethasone for relapsed multiple myeloma. N Engl J Med 2005;352:2487-98.

10. Mitsiades N, Mitsiades CS, Richardson PG, et al. The proteasome inhibitor PS-341 potentiates sensitivity of multiple myeloma cells to conventional chemotherapeutic agents: therapeutic applications. Blood 2003;101:2377-80.

11. Berenson JR, Yang HH, Sadler K, et al. Phase I/II trial assessing bortezomib and melphalan combination therapy for the treatment of patients with relapsed or refractory multiple myeloma. J Clin Oncol 2006;24:937-44.

12. San Miguel JF, Schlag R, Khuageva NK, et al. Bortezomib plus melphalan and prednisone for initial treatment of multiple myeloma. 
N Engl J Med 2008;359:906-17.

13. Palumbo A, Avonto I, Bruno B, et al. Intermediate-dose melphalan $\left(100 \mathrm{mg} / \mathrm{m}^{2}\right) /$ bortezomib/thalidomide/dexamethasone and stem cell support in patients with refractory or relapsed myeloma. Clin Lymphoma Myeloma 2006;6:475-7.

14. Roussel M, Moreau P, Huynh A, et al. Bortezomib and high-dose melphalan as conditioning regimen before autologous stem cell transplantation in patients with de novo multiple myeloma: a phase 2 study of the Intergroupe Francophone du Myelome (IFM). Blood 2010;115:32-7.

15. Attal M, Harousseau JL, Facon T, et al. Single versus double autologous stem-cell transplantation for multiple myeloma. N Engl J Med 2003;349:2495-502.

16. Cavo M, Tosi P, Zamagni E, et al. Prospective, randomized study of single compared with double autologous stem-cell transplantation for multiple myeloma: Bologna 96 clinical study. J Clin Oncol 2007;25:2434-41.
17. Adams J. The proteasome: a suitable antineoplastic target. Nat Rev Cancer 2004;4:349-60.

18. Rajkumar SV, Richardson PG, Hideshima T, Anderson KC. Proteasome inhibition as a novel therapeutic target in human cancer. J Clin Oncol 2005;23:630-9.

19. Podar K, Gouill SL, Zhang J, et al. A pivotal role for Mcl-1 in Bortezomib-induced apoptosis. Oncogene 2008;27:721-31.

20. Chew E, Filshie R, Wei A. Development of fatal bortezomib induced acute lung injury despite concurrent therapy with high-dose dexamethasone. Leuk Lymphoma 2007;48:212-3.

21. Gotoh A, Ohyashiki K, Oshimi K, et al. Lung injury associated with bortezomib therapy in relapsed/refractory multiple myeloma in Japan: a questionnaire-based report from the "lung injury by bortezomib" joint committee of the Japanese society of hematology and the Japanese society of clinical hematology. Int J Hematol 2006;84:406-12. 